\title{
Teaching Public Health Administration
}

\author{
JOHN J. HANLON, M.D., M.P.H.
}

PUBLIC HEALTH administration encompasses the practical application of knowledge for the general public good. Therefore, to the greatest extent possible, identification with the realities of daily work and its problems is fundamental to its adequate teaching. As with clinical medicine, the teaching of public health administration is best done at the bedside of the patient. In our field the patient is the social community, and the best way for the student to learn about the administration of public health programs is necessarily in relation to the community. Some people have questioned whether public health administration can be "taught" in contrast to being "learned." They advocate, in effect, exclusive recourse to the "school of hard knocks," or learning exclusively by trial and error. Such an approach has certain limitations. A significant number of errors are inevitable and tend not to be recognized as errors; therefore, they may be compounded and perpetuated. Certainly, there is something of value to be obtained from the experience of others. However, mere exposure to their knowledge and experience tends to be sterile and unrewarding, especially in an applied, dynamic, and variable field such as public health administration.

It would therefore seem obvious that the teaching of this subject, in the best sense, has a role for the academic institution on the one hand and for the operating health agency as a learning laboratory on the other. In addition,

Dr. Hanlon is director of Community Health Services, City of Philadelphia, and chairman, Department of Preventive Medicine, Temple University School of Medicine. This excerpt is taken from the paper he presented at the Third Conference of Directors of Schools of Public Health in Serra Negra, Brazil, September 22-28, 1963. it is obvious that these roles must be intimately interlinked and related to each other.

The academic institution, or school of public health, may employ many different techniques and approaches. Of these, formal lectures are probably the most common, yet the least satisfactory. This is not meant to imply that lectures have no place in graduate education in public health administration. On a selective basis, lectures may be valuable in summarizing a subject or topic. Generally speaking, it is best that a single, well-qualified faculty member be responsible for a lecture series, although occasionally he may bring in carefully selected and highly qualified specialists as guest lecturers for the presentation of selected topics. Much better than lectures are seminars and group discussions in which students can be divided into groups of 10 or 12 to facilitate and encourage the freest possible flow and presentation of ideas and opinions. A faculty member and, if possible, a visiting operational expert from the outside should direct each group, preferably in the roles of consultant and resource person rather than discussion leaders. If at all possible, it is best to give students, on a rotating basis, the responsibility for leadership of the discussion.

Whichever didactic approach is followed, guided reading of professional books and periodicals is an integral part. Material that includes varying points of view encourages individual questioning and discussion by the students. Reading assignments should not be made in a general sense or in a vacuum, but should be done selectively, with experienced teachers pointing out not only the different viewpoints but also the different theories and practices. It should be recognized and emphasized to the student that textbooks in public 
health administration necessarily deal essentially with theories and broad principles, and because of this represent an ideal, test tube, or controlled situation which must be adapted to the exigencies of real-life situations.

Not infrequently, students of public health are required to write papers or theses on assigned subjects. If this is done essentially to occupy the time of the students or to give them something to do, as unfortunately sometimes is the case, the practice is of questionable value and becomes a useless and irritating chore. On the other hand, a useful purpose may be served if $(a)$ the assigned subject is of interest and value to the students, $(b)$ if they have received adequate guidance on preparation from experienced faculty members and other knowledgeable individuals, and (c) if the subject is presented before the group of students for discussion.

Increasingly, schools of public health can obtain a variety of teaching aids such as films and exhibits. Review and careful selection is in order to see that they serve a useful purpose and that they are related to and integrated with all other learning experiences of the student. It is fruitless to use teaching materials simply because they are available.

Frequently, schools of public health have their students make field trips. Unfortunately, these are often useless and time consuming because of the manner in which they are conducted and the limited time available. There is serious question as to the educational value of visiting a series of offices or inactive clinic quarters, or of merely looking at a water treatment plant. If sufficient time is available for demonstration and discussion, certain types of field trips can be of educational value. They should be carefully selected and discussed with the students both before and after the trip, and, if possible, conducted by an experienced faculty member in company with an individual responsible for the installation or program visited. A special type of field trip which may be of definite value is one in which each student spends one day or more in the field with a public health nurse, a sanitarian, a social case worker, or other field workers. If a school provides for suitable field trips, they should include visits not only to official public health agencies but also to the activities of voluntary health agencies, other governmental agencies, and industry.

An unusual and valuable type of educational field visit was used for a number of years by one of the schools of public health in the United States. It illustrates the manner in which the academic institution and the operating health agency may join intimately for training purposes. At the beginning of the academic year, the class of students was divided into 7 groups of about 10 or 12 students, with a faculty advisor for each group. One student in each group was designated as the "health officer," and each group was related to a local health department in the area. The local health officers and members of their staffs came to the school once a week to meet in group discussion with respective student groups. Meanwhile, each group of students was assigned to a room, into which was "fed" all kinds of material and data relating to their assigned health department. If a communicable disease case was reported to the local health department, a copy of the report was sent to the student group. Weekly, monthly, and annual reports were accumulated and kept up to date. The students were responsible for the development of various epidemiologic charts and other similar materials. Not only was the teaching of public health administration related to the real-life needs of the seven local areas, but the material used in the teaching of biostatistics and epidemiology was related to the actual experience in these areas. This was in contrast to the usual recourse to artificial or outdated information.

After the school year had proceeded for about 6 weeks, all teaching within the school was stopped, and both students and faculty members spent a week in one of the seven areas. During that week, the students, under the guidance of a faculty member and the local health director and members of his staff, not only saw the health department in action but also observed the meetings of the local government, medical society, parent-teachers associations, farm, labor, and other groups. There was also opportunity for numerous field visits with members of the health department staff, as well as with individuals in other governmental and nongoverrmental agencies. Throughout the 
week, each student group was responsible for gathering data for a careful evaluation of the total community and its health needs and programs. A particularly important part of the week's experience was the opportunity for each student to live with a family in the community and to learn firsthand how they, the consumers, felt about health needs and local plans and programs.

After a week in the field, the students and faculty returned to the school with more than enough "grist for their educational mill" for the rest of the academic year. Group discussions were continued with the faculty and various visiting staff members of the respective health departments. As might be expected, the discussions were lively and fruitful. How did a certain situation or problem come about? Why was a certain decision made? On what basis was a particular program being pushed while another was not? Who were the key proponents or objectors in the community or local government to a certain course of action? Why could not more funds be obtained for a particular activity? Why was a certain individual put in charge of a particular program? These were but a few of the many real and practical questions that were raised and discussed relating to public health administration. As a followup toward the end of the academic year, the students singly or in groups, revisited their assigned communities for further investigation and to obtain firsthand answers to certain questions. The total experience, repeated for a number of years with different classes of students, appeared to be much more practical, stimulating, and fruitful than any previous approach. Such an approach to the teaching of public health administration has certain prerequisites in the form of available funds and facilities. However, less elaborate adaptations may be possible for a great many if not all schools of public health.

Before leaving the consideration of the role of the academic institution in the teaching of public health administration, one last word should be said about those responsible for the teaching. It is recognized that, because of its complex nature, public health administration involves the intermixture of a number of different disciplines such as medicine, nursing, en- gineering, law, political science, social science, and administrative management. It is only wise and practical to include all of these fields, in some way and to some extent, in the teaching of public health administration. Finally, it is most important that those responsible for teaching have three particular characteristics or qualities if they are to have the respect of their students and be of value to them. They must be empathetic if they are to establish the desirable rapport, they must be experienced if they are to gain respect, and they must be provocative if they are to encourage independent thought and analysis.

Some consideration must be given to the role of the other of the two predominant partners in the teaching of public health administration, the operating public health agency. By no means should the agency be passive in the teaching process. There is good reason for it not to be. After all, it is the organization for which the students are being trained and, as such, it should have an active interest in what is being taught and how it is being taught. The operating agency can participate in many ways. Since most of the teaching should be based upon practice and experience, it is desirable that appropriate staff members of the operating public health agency have academic appointments as lecturers or professors in the schools of public health. Such appointments should by no means be nominal, but should involve teaching responsibilities either in the school setting, in the field, or in both. The operating health agency has an important contribution to make in the development of valuable teaching material and in providing it to schools of public health. This may take many forms and include such items as reporting and describing cases or epidemics of disease, outlining programs, and providing operational budgets, organizational charts, and annual reports of good quality.

Since education in public health administration should stress practical and real-life situations, operating health agencies and the governments that support them might offer apprenticeships, traineeships, and residencies preceding or following formal education in the academic setting. Increasing consideration is being given to a period of residency training in 
a health agency as part of the requirement for a graduate degree in public health. This training should apply particularly to those who aspire to a career in public health administration. Along the same line, a forward-looking, operating public health agency could develop and carry out, in collaboration with schools of public health, various inservice training programs for their own staff members. By this means, such staff members may become of greater value to any students who might be sent by the schools of public health for field visits or residency training. Probably the most desirable sequence of events in training individuals for public health administration consists of a period of about a year as a trainee in an operating health agency during which time the individual is exposed to various practical experiences. This should be followed by a year of academic training in a school of public health, supplemented by a period of a number of months of residency training in another health agency.

Finally, the operating public health agency should be as active a possible in exploring and applying new approaches and programs in public health administration. In a field as complex and dynamic as public health administration, such activities are of great importance and value both to the operating health agency and to the academic institutions responsible for supplying them with qualified personnel. Through such endeavors, those of us responsible to any degree for the future may provide by example the characteristics of imagination, initiative, efficiency, leadership, and dignity in the practice of public healh administration.

\section{Regulation of Septic Tanks and Wells}

In a stepped-up attack on health problems caused by the indiscriminate use and failures of septic tanks and private wells in suburban areas of the country, the Public Health Service has written and sent to all State health departments a model law, designed for passage by State legislatures, to regulate the use of individual wells and septic tanks.

At present no State has legislation specifically to establish policies to limit use of individual water supply and sewerage facilities in suburban areas.

The proposed legislation would require urban municipalities to prepare, adopt, and submit to State health departments for approval comprehensive plans for water and sewerage facilities, including particularly areas of proposed development. Provisions would also authorize municipalities in an area to cooperate in meeting areawide needs and to receive technical assistance from the State in preparing official plans for water supply and sewerage systems. An optional section authorizes a
State to make grants to municipalities for preparing official plans and related studies.

The Public Health Service will offer continuing support to the States by providing technical assistance and consultation in sanitation matters, Dr. Luther L. Terry, Surgeon General of the Public Health Service, stated. He said, "Adoption of the model law, plus the provision of services, will assure that sudden menaces to health arising from the failure of individual systems and conflict between different portions of community systems will be rare, and the unnecessary expense of replacing inadequate systems will be kept to a minimum." The legislation will also, he said, help to assure the orderly development of urban areas, thus reducing wasteful urban sprawl, and go a long way toward meeting the water needs of urban areas.

The Advisory Commission on Intergovernmental Relations helped develop the model law, and the Association of State Health Offcers recently endorsed its principles. 


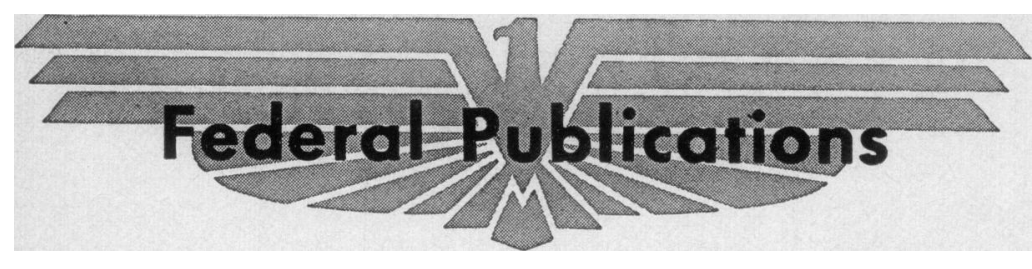

Cancer Manual for Public Health Nurses. PHS Publication No. 1007; 1963; 112 pages; 55 cents. Written specifically for public health nurses, this information is also suitable for student and staff nurse education in schools and hospitals. Text includes information about cancer of selected sites, with emphasis on functions o1 the public health nurse in a cancer control program, and care of the whole patient, psychological as well as physical.

Programing and Equipping Hospital Departments. PHS Publication No. 930-D-14; 1963; 72 pages; 45 cents. Provides guidelines for hospital planners in programing and equipping general hospitals having from 50 to 200 beds. The material is presented in question format, selected to stimulate thinking without restricting the initiative of planners. The questions cover more than 20 hospital departments or services.

Grants for Research in Community Health. PHS Publication No. 1090; October 1963; leaflet. Describes briefly the broadened research grants program in community health in the Bureau of State Services, Public Health Service. Grants may now be awarded to support research in chronic diseases, communicable diseases, community health services, and dental public health as well as accident prevention, nursing, and hospital and medical facilities.

Biological Products. PHS Publication No. 50; revised April 15, 1963; 78 pages.

This publicaton, distributed as an information guide, especially for physicians, is the annual edition of establishments and products which have been licensed pursuant to sec. 351 of the Public Health Service Act (58 Stat. 682) for the manufacture and sale, barter or exchange, interstate, and for export or import, of viruses, serums, toxins, and analogous products, and the trivalent organic arsenic compounds.

Requests for the publication and current supplements should be addressed to Director, Division of Biologics Standards, National Institutes of Health, Bethesda, Md.

Endocarditis: Bibliography compiled from the English language, 1957-1962. PHS Publication No. 1064; 1963; 23 pages; 25 cents. Covers all articles included in the Index Medicus for the period January 1, 1957, through December 31, 1962, which deal with endocarditis. References are divided into categories covering etiology, manifestation, therapy, preventive measures, and epidemiology.

A Comprehensive Psychiatric Center. PHS Publication No. 1085; 1963 ; by Fritz A. Freyhan and Julia A. Mayo; 48 pages.

Presents a conceptual and practical framework for a new approach, the comprehensive treatment of patients with serious psychiatric disorders based on a functional understanding of the clinical and psychosocial aspects of mental illness. The material is based on a clinical research and demonstration project jointly sponsored by the National Institute of Mental Health and Saint Elizabeths Hospital, Washington, D.C. It deals with concept, functional design, and personnel training requirements of a comprehensive center. Inpatient service, day hospital, clinic and home services are presented as functionally linked basic units. Excerpts from a schizophrenic patient in comprehensive treatment illustrate the application center.

The material, which comprises text, illustrations, and photographs, should be of particular value to psychiatrists, public health officials, of the concept as practiced at the hospital administrators, social workers, and nurses who are concerned with establishment of and treatment in community mental health centers.

Psychopharmacology Handbook Volume II. Animal research in psychopharmacology. A compilation from the available world literature for 1960. PHS Publication No. 1006 (Public Health Bibliography Series No. 40); 1963; 529 pages; \$3. The articles analyzed and abstracted are compiled from a selection of the world literature for 1960 in the area of animal studies in psychopharmacology. The abstracts cover the effects of psychotropic drugs which primarily affect voluntary behavior. The abstracts are categorized according to drug, animal species, and type of measure or method employed in the study, that is, behavioral, physiological, and neurological.

Make Each Person Count. PHS Publication No. 1054; 1963; by Elsie K. Y. Ho; 23 pages. Directed to the nursing home administrator, this booklet emphasizes the important role he assumes as leader and model to others. Experiences encountered daily in nursing homes are described to indicate areas for implementing mental health approaches. Thoughtful handling of families and the public is stressed. Pictures are used to illustrate specific points. This publication should also be of interest to consultants, supervisors, faculty, and others reaching nursing home personnel.

This section carries announcements of new publications prepared by the Public Health Service and of selecfed publications prepared with Federal support.

Unless otherwise indicated, publications for which prices are quoted are for sale by the Superintendent of Documents, U.S. Government Printing Office, Washington, D.C., 20402. Orders should be accompanied by cash, check, or money order and should fully identify the publication. Public Health Service publications which do not carry price quotations, as well as single sample copies of those for which prices are shown, can be obtained without charge from the Public Inquiries Branch, Public Health Service, Washington, D.C., 20201.

The Public Health Service does not supply publications other than its own. 